\title{
The Influence of Human T-Lymphotropic Virus 1 on Patients Coinfected by the Helminth Strongyloides stercoralis
}

\author{
Larissa Rodrigues Bosqui, Taylon Felipe Silva*, Raquel Arruda Sanfelice, Laís Fernanda Machado, \\ Érika Caroline Steinle, Bianca Arranzato Bertasso, Marina Letícia Rezende Mantovani, Gabriela \\ de Alcantara Dalevedo, Milena Menegazzo Miranda-Sapla, Ivete Conchon-Costa, Wander Rogerio \\ Pavanelli, Francine Nesello Melanda and Idessania Nazareth Costa
}

Department of Pathological Sciences, Laboratory of Parasitology of Neglected Diseases and Cancer, Londrina State University, Brazil

*Corresponding author: Taylon Felipe Silva, Centro de Ciências Biológicas, Departamento de Ciências Patológicas, Laboratório de Parasitologia das Doenças Negligenciadas e Câncer, Universidade Estadual de Londrina-UEL-Rodovia Celso Garcia Cid, Campus Universitário, Cx. Postal 6001, CEP 86051-990, Londrina, PR, Brazil, Tel: +055-43-3371-4539

\begin{abstract}
Strongyloides stercoralis is the helminth which causes strongyloidiasis, a neglected disease, with a global prevalence estimated at 60 million people infected, principally in tropical regions. The parasite's proliferation occurs mainly in immunosuppressed hosts, in particular, patients carrying Human T-lymphotropic virus 1 (HTLV-1), which is responsible for the infection of cells of the immune system. As a result, we aimed to identify and discuss clinical and pathological aspects of infection by $S$. stercoralis in patients carrying HTLV-1. This is an exploratory study, of the literature review type. The search was undertaken in the PubMed, Scielo, Web of Science, Science Direct and Biblioteca Virtual emSaúde (BVS) databases in August 2016. The criteria for the inclusion of articles were: Language, published in the last 20 years, and to be relevant to the guiding question. After reading of the titles, 60 articles were excluded, and after reading of the abstracts, a further 70. Of the 56 articles remaining, 16 were excluded after reading the article in full. After analysis of the material, only 40 studies met the criteria established. The studies showed that this type of coinfection is found in the same specific population groups which are vulnerable to the diseases, as well as immunomodulation of the Th2 pattern, promoted by the presence of $S$. stercoralis and the difficulties related to the diagnosis of Strongyloidiasis. It is concluded that it is necessary to screen for HTLV-1in cases of infection by S. stercoralis, so as to initiate fast and efficient treatment against this coinfection.
\end{abstract}

\section{Keywords}

HTLV-1, Strongyloidiasis, Coinfection

\section{Introduction}

Strongyloides stercoralisis the helminth which causes strongyloidiasis, a neglected disease with global prevalence estimated at 60 million people infected [1]. This helminth is more common in the tropical regions [1]. The main form of infection is through the filariform larvae penetration through the skin of the host, who commonly does not present symptoms. The most serious form of dissemination, however, occurs principally in immunosuppressed hosts, who become more susceptible due to the host organism's inability to combat the infection $[2,3]$.

In immunocompetent individuals, infection by HTLV1 is a relatively insignificant problem. On the other hand, patients with immunosuppression, caused mainly by the use of corticosteroids, has been shown to be involved in the development of disseminated strongyloidiasis [4]. HTLV-1 is a retrovirus responsible for the infection of cells of the immune system, mainly T CD4+ lymphocytes, although it also infects T CD8+ and Natural Killer (NK) cells. As a result, this retrovirus is directly related to leukemia. Contagion may occur through breast-feeding, sexual contact and blood products, such as syringes or hypodermic needles. Contagion may also occur by direct contact with blood, like in blood transfusion $[5,6]$.

Citation: Bosqui LR, Silva TF, Sanfelice RA, Machado LF, Steinle EC, et al. (2019) The Influence of Human T-Lymphotropic Virus 1 on Patients Coinfected by the Helminth Strongyloides stercoralis. Int J Trop Dis 2:016

Accepted: February 07, 2019; Published: February 09, 2019

Copyright: (C) 2019 Bosqui LR, et al. This is an open-access article distributed under the terms of the Creative Commons Attribution License, which permits unrestricted use, distribution, and reproduction in any medium, provided the original author and source are credited. 
It is estimated that, worldwide, approximately 10 to 20 million individuals are infected by the retrovirus, the majority not presenting symptoms [2]. On the other hand, the virus can cause immunosuppression in symptomatic cases, with disseminated forms of strongyloidiasis frequently being found [7]. It has been evidenced that patients carrying HTLV-1 present a probability 2.4 times greater of developing strongyloidiasis than individuals who have not been infected by this retrovirus [8].

The high rate of infection by $S$. stercoralis in patients with HTLV-1 may be explained by the impairment of the immune system caused by the virus, resulting in the organism's inability to combat the parasite [7]. Furthermore, the virus is able to modulate the host's immune response, causing spontaneous proliferation of infected T lymphocytes which secrete IFN- $\gamma$, thus promoting predominance of the Th1 pattern immune response. In addition to this, there is a reduction in the production of IgE, eosinophils and IL-4 and IL-5 - responsible for the Th2 pattern immune response which are important in the defense against helminths $[7,9]$. Consequently, it may be inferred that the immunosuppression caused by HTLV-1 may act as a predisposition for disseminated strongyloidiasis, worsening symptoms and possibly resulting in death [10].

Since patients with S. stercoralis coinfected by HTLV1 present several clinical and pathological aspects, such as changes in immune response and decreased efficacy of antiparasitics, this review aims to identify and discuss clinical and pathological aspects of infection by $S$. stercoralis in patients carrying HTLV-1.

This is an exploratory study, of the literature review type. In order to identify studies on the topic, searches were made in the following databases: PubMed, hosted by the National Center for Biotechnology Information (NCBI), Scielo, Web of Science, Science Direct and the Biblioteca Virtual emSaúde (BVS). The searches used the following terms: HTLV-1, Human T-lymphotropic virus 1, and Strongy, as a form of prefix for encompassing words derived from this descriptor.

The search, and the extraction of the data, took place between the $4^{\text {th }}$ and $25^{\text {th }}$ August 2016. Articles were included which met the following inclusion criteria: To be in the Portuguese or English languages, to have been published in the last 20 years (1996 to August 2016) and to be relevant to the guiding question. The following were excluded: informal case reports, book chapters, dissertations, theses, reports and news from the media, editorials and non-scientific texts.

The studies selection followed three stages: a) Evaluation of the titles, b) Reading of the abstracts and c) Reading of the manuscripts in full. After this stage, the data of interest were extracted and recorded in standardized Excel spreadsheets.

\section{Results and Discussion}

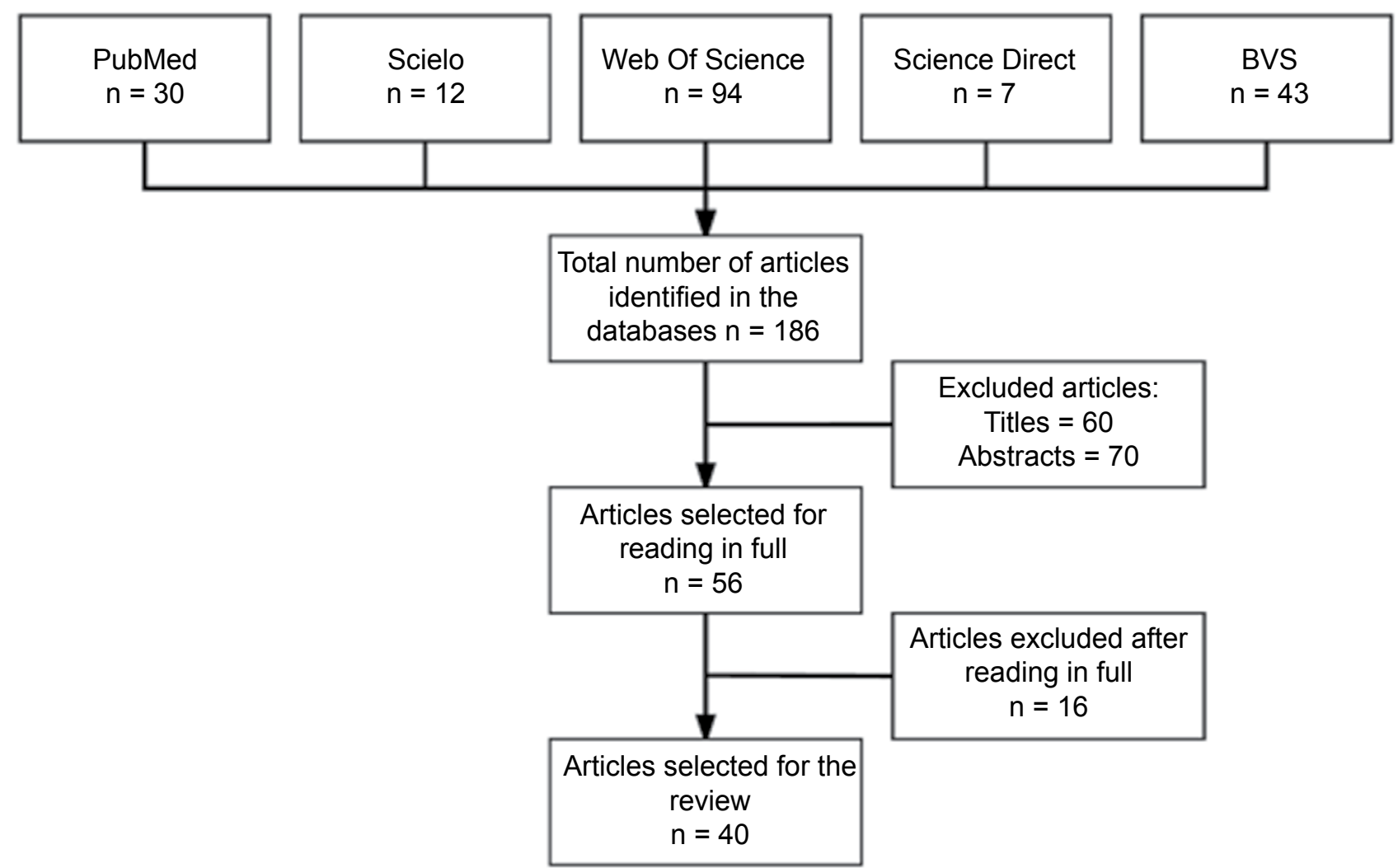

Figure 1: Flowchart of the selection of articles for the review. Of the articles selected for the work, all were published in English. Regarding year of publication, it was observed that 2013 was the year with the highest rate of publication, with a total of five articles. As shown in Figure 2, in the years 1996 and 2012 no articles relevant for this review were published. 
Under the search strategy adopted, a total of 186 articles were found. From the results found, $30(16 \%)$ works belonged to the PubMed database, $12(6 \%)$ to Scielo, $94(51 \%)$ to Web of Science, $7(4 \%)$ to Science Direct and $43(23 \%)$ to the Biblioteca Virtual de Saúde (Figure 1). After reading of the titles, 60 articles were excluded, and after reading of the abstracts, a further 70. Of the 56 articles remaining, 16 were excluded after reading the article in full. After analysis of the material, therefore, it was observed that 40 studies met the criteria established, and formed this study's final sample (Figure 2).

Strongyloidiasis is common in tropical and subtropical areas, with high prevalence in Africa, Asia and South America [2]. In addition, co-infection of this helminth with HTLV-1 occurs in regions where both are endemic, such as the southwestern and Okinawa islands in Japan [11], Jamaica [12] and Brazil. Specifically in Brazil, in the State of Pará, infection by both HTLV-1/2 and by $S$. stercoralis is considered endemic. Due to this, the Center for Tropical Medicine (Núcleo de Medicina Tropical - NMT), of the Federal University of Pará (UFPA) undertook research in order to identify these two infections, and observed that in the 91 patients infected by HTLV, the frequency of $S$. stercoralis was $14.3 \%$ ( $n$ = 6) in patients infected with HTLV-1 and $11.1 \%$ ( $\mathrm{n}=$ 2) among patients infected by HTLV-2 [13]. The same question was studied by Satoh, et al. [14], in Japan, in which 31 patients were diagnosed as carrying HTLV-1. Among these patients, 19 (61.0\%) were infected by $S$. stercoralis. Furthermore, Einsiedel, et al. [15], in a study undertaken between 2000 and 2010, demonstrated that adults of the indigenous population of the arid region of Australia who carried HTLV-1 had a high rate of infection by S. stercoralis. In addition to this, the authors emphasized that the environmental conditions, poor economic resources and social deprivation contribute to the mortality of coinfected indigenous adults.

In spite of surveillance for infection by S. stercoralis being more common in tropical and subtropical regions where infection by this intestinal helminth is endemic, it is increasingly common in other areas, due to patterns of immigration in these regions [16]. Strongyloidiasis generally promotes chronic and asymptomatic infections in immunocompetent individuals, whose effector mechanisms of immune cells impede the parasite's dissemination in the intestine. In immunocompromised individuals, however, the number of parasites is found to be high, which may cause hyperinfection or disseminated infection, sometimes resulting in death $[1,4,17]$.

Infection by HTLV-1 is capable of causing severe compromise of patients' immune status, because it induces chronic infection of T CD4+ cells. Although the majority of infected people remain asymptomatic, development of inflammatory syndromes, neoplastic diseases and secondary infections, including strongyloidiasis, can occur $[18,19]$. As a result, it is recommended that HTLV-1 should be screened for in cases of infection by $S$. stercoralis, in particular when other risk factors are apparent, such as the use of glucocorticoids, which accelerate the conversion of rhabditoid larvae to the infective filariform form of the parasite's larvae [20,21], the aim being to initiate efficient treatment against this coinfection $[2,18,22]$.

One of the factors responsible for this coinfection is the fact that T cells infected by the HTLV-1 virus promote a Th1 immune response, with a high level of Interferon Gamma (IFN- $\gamma$ ), low quantities of interleukin 4 (IL-4), reduction in the number of eosinophils [2] and reduction in IgE antibodies which are important in combating parasitic infections [7,23-26]. Patients

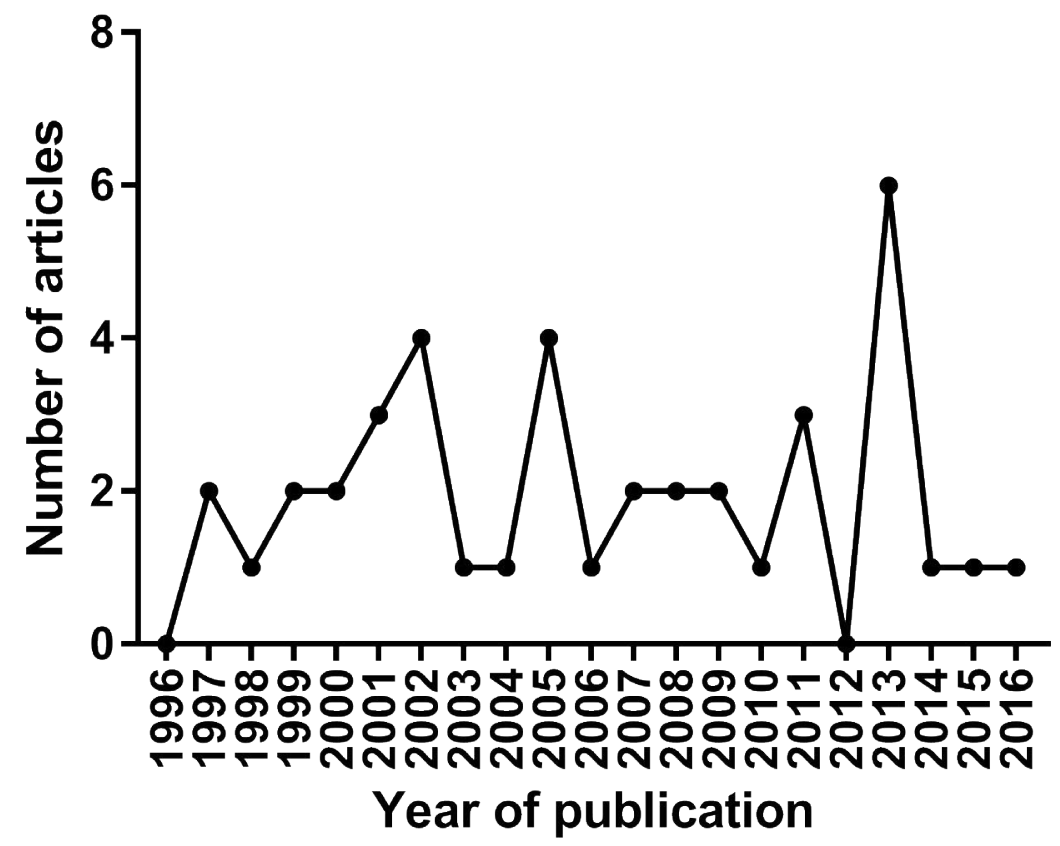

Figure 2: Characterization by year of publication of the articles related to coinfection by HTLV-1 and S. stercoralis. 
coinfected with $S$. stercoralis and HTLV-1, not present haematological alterations, however, we verified the existence of reports of cases that evaluated this association [4,27]. As under normal circumstances the response against parasitic infections is of the Th2 type, the negative regulation of the anti-inflammatory response in patients coinfected with $S$. stercoralis and HTLV-1 facilitates disseminated strongyloidiasis [10,17]. On the other hand, the negative regulation of IL-4 in individuals coinfected with $S$. stercoralis and HTLV-1 can cause deficient IgE responses which are important in controlling this parasite. Hence, infection by the HTLV-1 virus is an important risk factor for developing severe disseminated strongyloidiasis, given that these are comorbidities which influence the host's immune response [10,27-30]. If on the one hand it is clear that HTLV-1 favors the appearance of severe forms of strongyloidiasis, studies are necessary to determine how it is that $S$. stercoralis changes the course of infection by HTLV-1 [31].

Acting in both directions, strongyloidiasis seems to facilitate the replication of the HTLV-1 virus and shorten the latency period, as - subsequent to the use of antiparasitic agents - reduction in the levels of the virus's mRNA, and an increase in tumor necrosis factor alpha (TNF- $\alpha$ ) and IFN- $\gamma$ were evidenced $[17,32,33]$. Levels of IFN- $\gamma$ and TNF- $\alpha$ are higher in patients infected only with HTLV-1 than among those coinfected with $S$. stercoralis, as ascertained in a study with 60 patients in Bahia, which compared certain immunological aspects of patients with HTLV-1 who were or were not coinfected with S. stercoralis, before and after treatment. Additionally, it was ascertained that after treatment for strongyloidiasis, the levels of TNF- $\alpha$ increased when compared with levels prior to treatment, indicating that strongyloidiasis exercises an important immunomodulatory role in the host, in some manner facilitating viral replication. Regarding the levels of IL-5 and IL-10, significant statistical differences were not found between the groups with and without coinfection, before or after treatment for strongyloidiasis [17]. In contrast, Porto, et al. [26], reported that the frequency of interleukin 10 (IL-10)-secreting CD8+ T cells is higher in patients carrying HTLV-1 who are coinfected with $S$. stercoralis, when compared with HTLV-1 positive patients who are not coinfected. The increase in IL-10 is responsible for suppressing the activity of macrophages and the proliferation of lymphocytes, reducing the synthesis of IFN- $\gamma$, once more providing evidence of a close relationship between the two morbidities. These results suggest that patients infected by HTLV-1, even when asymptomatic, must be considered as a high risk group for infection by S. stercoralis $[25,26,34]$.

It is known that IL-5 plays an important role in infections by helminths, acting both in the activation of $B$ cells for production of IgE and in the activation of eosinophils. The regulatory T cells (CD4+CD25+FoxP3+), however, are known for their immunoregulatory and downregulatory function of effector $\mathrm{T}$ cells. In one study undertaken with 13 coinfected patients, between November 2005 and August 2007, it was ascertained that low levels of IL-5 are produced in response to stimulation by $S$. stercoralis, which can lead to a decrease in the eosinophil count. In addition to this, there was an increase in the number of regulatory $T$ cells in coinfected patients when compared with the healthy control group [35]. The production of lymphocytes expressing this phenotype was inversely correlated with the IL-5 expression levels. This increase in Tregmay explain the low number of eosinophils in patients with $S$. stercoralis who are coinfected by HTLV-1, impeding an appropriate and efficacious inflammatory response against strongyloidiasis, thus providing an environment which is propitious for the development of parasites. These results reveal that infection by HTLV-1 reduced sensitivity for detection of IgE-specific S. stercoralis, the immediate hypersensitivity reaction and the sensitivity of these tests in the diagnosis of strongyloidiasis, leading to delay in diagnosis and increasing the possibility of more severe cases of coinfection. As a result of this, immunological tests were developed with the aim of increasing the specificity of $S$. stercoralis antibodies, both in blood tests and immediate hypersensitivity tests, so as to allow better diagnosis, bearing in mind the severity and incidence of the disease [13].

In relation to the treatment, studies by Sasaki, et al. [21] showed that $28.6 \%$ of patients with $S$. stercoralis treated with thiabendazole experienced recurrence after the treatment, while this is not reported in treatment with Ivermectin, a medication used in the treatment of this parasitic infection. Hence, Ivermectin can eradicate $S$. stercoralis more efficiently, its use being important in immunodeficient patients, as is the case in infections by HTLV-1 [21,36,37].

Additionally, Satoh, et al. [38] ascertained that coinfected patients presented cure rates which were significantly lower (40.6\%) than among patients who were HTLV-1 negative (66\%) when treated with the anti-helminthic agent Albendazole ( $p$-value < 0.05). The serum IgE and IgG4 antibodies from the peripheral blood of patients with this coinfection were analyzed, and it was ascertained that there was a reduction in IgE and an increase in IgG4 ( $p$-value $<0.05$ ) in patients after they were treated with Albendazole but were not cured from strongyloidiasis. Besides this, it was verified that coinfected patients demonstrated a higher frequency in the expression of the IFN- $\gamma$ and TGF- $\beta 1$ cytokines, while patients infected by $S$. stercoralis but who were HTLV-1 negative did not present expression of these cytokines. According to the authors, coinfected patients, with high levels of IFN $-\gamma$ and TGF- $\beta 1$, reduction in IgE, and increase in IgG4, presented low rates of cure ( $p$-value < 0.01) [38-40]. 
The Th2 response fundamental in combating helminths, as it establishes an eosinophilic response and promotes the production of IgE, suggesting that this coinfection may impair this type of response, which is in line with the evidence for therapeutic failure with Ivermectin and Albendazolin these patients [2,7].

Although the treatments for infections by HTLV-1 are still non-specific, the knowledge of the potential for coinfection with HTLV-1 and S. stercoralis may facilitate early diagnosis and allow more successful treatment for infection by these helminths [41]. It follows that performing diagnostic tests for HTLV-1 in patients with strongyloidiasis but without hypereosinophilia would be worth considering as a clinical conduct [42].

Surveillance actions, such as the adoption of initial triaging and prophylactic treatment, above all in individuals with epidemiological risks for parasitosis, must be taken into account, as early treatment for strongyloidiasis reduces the occurrence of the disseminated form of the infection, in particular in the case of immunocompromised patients who are more susceptible to infection.

As a result, the study's basis, which contributed directly to the construction of the present bibliographic survey, evidences the high occurrence of coinfections in the aspects related to the immune system, diagnosis and treatment in patients carrying these morbidities. Consequently, we conclude that screening for HTLV1 in cases of infection by $S$. stercoralis is highly recommendable, especially when other risk factors are apparent, so that quick and efficient treatment may be initiated against this coinfection.

\section{References}

1. Schär F, Trostdorf U, Giardina F, Khieu V, Muth S, et al. (2013) Strongyloides stercoralis: Global distribution and risk factors. PLoS Negl Trop Dis 7: e2288.

2. Carvalho EM, Da Fonseca Porto A (2004) Epidemiological and clinical interaction between HTLV-1 and Strongyloides stercoralis. Parasite immunol 26: 487-497.

3. Terashima A, Gotuzzo E, Alvarez H, Infante R, Tello R, et al (1999) Strongyloides stercoralis: Formas clínicas severas asociadas a infección por HTLV-1. Rev Gastroenterol 19: $35-40$.

4. Stewart DM, Ramanathan R, Mahanty S, Fedorko DP, Janik JE, et al. (2011) Disseminated Strongyloides stercoralis infection in HTLV-1-associated adult T-cell leukemia/ lymphoma. Acta haematol 126: 63-67.

5. Patricia Midori Murobushi Ozawa, Dênis Augusto Santana Reis, Mirian Ayumi Kurauti, Tuane Mayara Govêa Simões, Julie Massayo Maeda Oda, et al. (2012) Vírus linfotrópico de células T humano tipo 1 (HTLV-1): Implicações em doenças autoimunes. Semina: Ciências Biológicas e da Saúde 33: 83-96.

6. Mochizuki M, Watanabe T, Yamaguchi K, Yoshimura K, Nakashima S, et al. (1992) Uveitis associated with human T-cell lymphotropic virus type I. Am J Ophthalmol 114: 123129.
7. Hirata $\mathrm{T}$, Uchima $\mathrm{N}$, Kishimoto $\mathrm{K}$, Zaha $\mathrm{O}$, Kinjo $\mathrm{N}$, et al. (2006) Impairment of host immune response against Strongyloides stercoralis by human $\mathrm{T}$ cell lymphotropic virus type 1 infection. Am J Trop Med Hyg 74: 246-249.

8. Tanaka T, Hirata T, Parrott G, Higashiarakawa M, Kinjo T, et al. (2016) Relationship among Strongyloides stercoralis infection, human T-cell lymphotropic virus type 1 infection, and cancer: A 24-Year cohort inpatient study in Okinawa, Japan. Am J Trop Med Hyg 94: 365-370.

9. Kinjo T, Nabeya D, Nakamura H, Haranaga S, Hirata T, et al. (2015) Acute respiratory distress syndrome due to Strongyloides stercoralis infection in a patient with cervical cancer. Intern Med 54: 83-87.

10. Adedayo AO, Grell GA, Bellot P (2001) Case study: Fatal strongyloidiasis associated with human T-cell lymphotropic virus type 1 infection. Am J Trop Med Hyg 65: 650-651.

11. Satoh M, Toma H, Sato $Y$, Takara M, Shiroma $Y$, et al. (2002) Reduced efficacy of treatment of strongyloidiasis in HTLV-I carriers related to enhanced expression of IFN- $\gamma$ and TGF- $\beta 1$. Clin Exp Immunol 127: 354-359.

12. Robinson RD, Lindo JF, Neva FA, Gam AA, Vogel P, et al. (1994) Immunoepidemiologic studies of Strongyloides stercoralis and human T lymphotropic virus type I infections in Jamaica. J Infect Dis 169: 692-696.

13. Furtado KCYO, Carlos Araújo da Costa, Louise de Souza Canto Ferreira, Luisa Carício Martins, Alexandre da Costa Linhares, et al. (2013) Occurrence of strongyloidiasis among patients with HTLV-1/2 seen at the outpatient clinic of the Núcleo de Medicina Tropical, Belém, State of Pará, Brazil. Rev Soc Bras Med Trop 46: 241-243.

14. Satoh M, Kiyuna S, Shiroma $Y$, Toma H, Kokaze A, et al. (2003) Predictive markers for development of strongyloidiasis in patients infected with both Strongyloides stercoralis and HTLV-1. Clin Exp Immunol 133: 391-396.

15. Einsiedel L, Spelman T, Goeman E, Cassar O, Arundell M, et al. (2014) Clinical associations of Human T-lymphotropic virus type 1 infection in an indigenous Australian population. PLoS Negl Trop Dis 8: e2643.

16. Peters L, McCarthy AE, Faught C (2009) Secondary Strongyloides stercoralis prophylaxis in patients with human T-cell lymphotropic virus type 1 infection: Report of two cases. Int J Infect Dis 13: e501-e503.

17. Salles F, Bacellar A, Amorim M, Orge G, Sundberg M, et al. (2013) Treatment of strongyloidiasis in HTLV-1 and Strongyloides stercoralis coinfected patients is associated with increased TNFa and decreased soluble IL2 receptor levels. Trans R Soc Trop Med Hyg 107: 526-529.

18. Freites A (2008) Virus linfotrópico T humano 1 (HTLV-1), strongyloidiasis y escabiosis. Infecciones y asociaciones a considerar. Invest Clin 49: 455-457.

19. Nicolas Barros, Jorge Risco, Carlos Rodríguez, Cesar Sánchez, Elsa González, et al. (2013) CD4+ T cell subsets and Tax expression in HTLV-1 associated diseases. Pathog Glob health 107: 202-206.

20. Brites C, Goyanna F, França LG, Pedroso C, Netto EM, et al. (2011) Coinfection by HTLV-I/II is associated with an increased risk of strongyloidiasis and delay in starting antiretroviral therapy for AIDS patients. Braz $\mathrm{J}$ Infect Dis 15: 6-11.

21. Sasaki Y, Taniguchi T, Kinjo M, McGill RL, McGill AT, et al. (2013) Meningitis associated with strongyloidiasis in an area endemic for strongyloidiasis and human T-lymphotropic virus-1: A single-center experience in Japan between 1990 and 2010. Infection 41: 1189-1193. 
22. Zammarchi L, Montagnani F, Tordini G, Gotuzzo E, Bisoffi $Z$, et al. (2015) Persistent strongyloidiasis complicated by recurrent meningitis in an HTLV seropositive Peruvian migrant resettled in Italy. Am J Trop Med Hyg 92: 12571260.

23. Hayashi J, Kishihara Y, Yoshimura E, Furusyo N, Yamaji K, et al. (1997) Correlation between human T cell lymphotropic virus type-1 and Strongyloides stercoralis infections and serum immunoglobulin $E$ responses in residents of Okinawa, Japan. Am J Trop Med Hyg 56: 71-75.

24. Neva FA, Filho JO, Gam AA, Thompson R, Freitas V, et al. (1998) Interferon-gamma and interleukin-4 responses in relation to serum IgE levels in persons infected with human T lymphotropic virus type I and Strongyloides stercoralis. J Infect Dis 178: 1856-1859.

25. Porto AF, Neva FA, Bittencourt H, Lisboa W, Thompson $R$, et al. (2001) HTLV-1 decreases Th2 type of immune response in patients with strongyloidiasis. Parasite immunol 23: $503-507$.

26. Porto AF, Santos SB, Muniz AL, Basilio V, Rodrigues W Jr, et al. (2005) Helminthic infection down-regulates type 1 immune responses in human $\mathrm{T}$ cell lymphotropic virus type 1 (HTLV-1) carriers and is more prevalent in HTLV-1 carriers than in patients with HTLV-1-associated myelopathy/tropical spastic paraparesis. J Infect Dis 191: 612-618.

27. Ratner L, Grant C, Zimmerman B, Fritz J, Weil G, et al (2007) Effect of treatment of Strongyloides infection on HTLV-1 expression in a patient with adult T-cell leukemia. Am J Hematol 82: 929-931.

28. Chieffi PP, Chiattone CS, Feltrim EN, Alves RC, Paschoalotti MA (2000) Coinfection by Strongyloides stercoralis in blood donors infected with human T-cell leukemia/lymphoma virus type 1 in Sao Paulo City, Brazil. Mem Inst Oswaldo Cruz 95: 711-712.

29. Gabet AS, Mortreux F, Talarmin A, Plumelle Y, Leclercq I, et al. (2000) High circulating proviral load with oligoclonal expansion of HTLV-1 bearing T cells in HTLV-1 carriers with strongyloidiasis. Oncogene 19: 4954-4960.

30. Hindy P, Parvin R, Hanna K, Gress F (2011) Strongyloidiasis presenting as duodenal obstruction in a patient infected with human T-cell lymphotropic virus type 1. Gastrointest Endosc 74: 439-441.

31. Porto MADF, Muniz ALN, Júnior JO, Carvalho Filho EMD (2002) Implicações clínicas e imunológicas da associação entre o HTLV-1 e a estrongiloidíase. Rev Soc Bras Med Trop 35: 641-649.

32. Plumelle $\mathrm{Y}$, Gonin C, Edouard A, Bucher BJ, Thomas L, et al. (1997) Effect of Strongyloides stercoralis infection and eosinophilia on age at onset and prognosis of adult T-cell leukemia. Am J Clin Pathol 107: 81-87.

33. Ramanathan R, Nutman TB (2008) Strongyloides stercoralis infection in the immunocompromised host. Curr Infect Dis Rep 10: 105-110.

34. Biswas HH, Kaidarova Z, Garratty G, Gibble JW, Newman $\mathrm{BH}$, et al. (2010) Increased all-cause and cancer mortality in HTLV-II infection. J Acquir Immune Defic Syndr 54: 290296.

35. Montes M, Sanchez C, Verdonck K, Lake JE, Gonzalez E, et al. (2009) Regulatory T cell expansion in HTLV-1 and strongyloidiasis co-infection is associated with reduced IL-5 responses to Strongyloides stercoralis antigen. PLoS Negl Trop Dis 3: e456.

36. Richter J, Schwarz U, Duwe S, EllerbrokH, Poggensee G, et al. (2005) Recurrent strongyloidiasis as an indicator of HTLV-1 infection. Dtsch Med Wochenschr 130: 1007-1010.

37. Hovette $P$, Tuan JF, Camara $P$, Lejean $Y$, Lo $N$, et al. (2002) Pulmonary strongyloidiasis complicated by E. coli meningitis in a HIV-1 and HTLV-1 positive patient. Presse Med 31: 1021-1023.

38. Satoh M, Toma H, Sato $Y$, Takara M, Shiroma $Y$, et al. (2002) Reduced efficacy of treatment of strongyloidiasis in HTLV-I carriers related to enhanced expression of IFNgamma and TGF-beta1. Clin Exp Immunol 127: 354-359.

39. Choksi M, Joseph AJ, Simon E, Shah A, Ramachandran J, et al. (2009) The association of HTLV-1 infection, persistent intestinal infection with Strongyloides stercoralis and gastrointestinal lymphoma. BMJ Case Rep bcr0720080373.

40. Lagacé-Wiens PR, Harding GK (2007) A Canadian immigrant with coinfection of Strongyloides stercoralis and human T-lymphotropic virus 1. Can Med Assoc J 177: 451-453.

41. Friedenberg F, Wongpraparut N, Fischer RA, Gubernick J, Zaeri N, et al. (1999) Case Report: Duodenal obstruction caused by Strongyloides stercoralis enteritis in an HTLV-1Infected Host. Dig Dis Sci 44: 1184-1188.

42. Alvarez-Falconí PP, Moncada-Vilela Z, Montero-Navarrete S, Hernandez-García JA (2013) Reporte de un caso de estrongiloidiasis con coinfección por HTLV-1 y onicomicosis. Revista de Gastroenterología del Perú 33: 348-351. 